\title{
Goal-Directed Behaviors in Marketing: The Role of Emotion, Volition, and Motivation
}

\author{
Richard P. Bagozzi \\ University of Michigan
}

\section{INTRODUCTION}

Much of marketing behavior is purposive. Yet little theory and even less research can be found in the literature concerning purposive marketing activities.

This special issue focuses upon the role of emotions in goal-directed consumption. Emotions perform different functions and operate at different levels under various stages of consumer decision making. The five articles presented in this issue reflect this. In the first article, Mano explores the moderating effects of emotions. Pleasantness and arousal interact with involvement to govern the course of information processing in a persuasion context.

In the next two articles, emotions function as intervening variables. Miller and Marks study the ability of emotions to mediate the effect of personality on product satisfaction. They operationalize emotions as positive and negative affects, where each component of affect consists of an aggregation of multiple discrete emotional responses. Sherman, Mathur, and Smith investigate the power of emotions to mediate the effects of environmental retail stimuli on shopping behaviors. Emotion here was conceived as a two-dimensional pleasure/arousal phenomenon.

Emotions function as well as important dependent variables in the fourth article, by Mooradian and Olver. Here emotions were measured through a number of positive affect and arousal/activity items. Gould 
then explores the functioning of moods as self-regulating mechanisms in consumption in the final article. The intriguing idea that people manage their moods through consumption activities is developed. This is done through a holistic process of self-interpretation, where moods are psychologically constructed as goal-directed activities.

\section{SUMMARY OF ARTICLES}

The role of affect in persuasion has been studied primarily as the impact of a unidimensional phenomenon, namely, pleasantnessunpleasantness, on information processing. Further, there is some discrepancy in the literature with respect to the effects found for positive mood on message elaboration, with some studies showing a decrease and others revealing an increase in elaboration. Mano addresses these issues head-on in an experimental investigation of the effects of pleasantness and arousal on persuasion outcomes (i.e., attitude) and information processing (i.e., message elaboration). Specifically, Mano manipulated involvement and message quality and treated pleasantness and arousal as measured variables (by asking people before the manipulations to indicate how pleasant and aroused they felt in response to a series of emotion-describing adjectives). Among other results, he found that pleasantness accentuated the interaction effect between involvement and argument quality on attitudes (i.e., a threeway interaction was found between pleasantness $\times$ involvement $\times$ argument quality). Moreover, high arousal led to more favorable attitudes under high but not low involvement. In addition, under low involvement, pleasantness and message elaboration were slightly negatively correlated, but under high involvement they were positively correlated. Mano's study clarifies the impact of affect on persuasion and information processing and suggests that task involvement is a key moderator.

The influence of different imagery-evoking strategies on responses to appeals in radio advertisements was investigated by Miller and Marks. The authors manipulated sound effects, vividness of verbal information, and instructions to imagine aspects of college football games to potential patrons. It was found that sound effects (i.e., presence/absence of clatter of fans entering a stadium, roaring of a crowd in reaction to a touchdown, and half-time marching band) were the most effective tactics in generating imagery and influencing positive feeling and attitudes toward the ad. Instructions to imagine were the least effective tactics, with vivid verbal messages only slightly less effective than sound effects. The propositional-representations theory was used to interpret the results, where it was argued that sound effects should more directly activate memory structures that contain perceptual information than the other tactics. That is, exposure to the 
sound effects vividly stimulated sights, sounds, and other sensations connected to attending football games.

Sherman, Mathur, and Smith examine the determinants of various shopping behaviors for consumers in fashion stores. Following a stimulus-organism-response paradigm, the authors put specific emphasis on the mediating role of emotions, which they operationalized as separate factors of pleasure and arousal. Four exogenous stimuli were investigated as aspects of the retail environment: social, overall store image, store design, and store ambiance. The dependent-variable measures of behavior included number of items purchased, amount of money spent in store, amount of time spent in store, and reactions to store environment. The findings generally confirmed predictions.

We know a great deal about how the confirmation or disconfirmation of expectations influences product satisfaction. But do personality and emotional responses also influence satisfaction? Mooradian and Olver answer this question by investigating the impact of extroversion and neuroticism on positive and negative consumption-based emotions, respectively, and how these emotions affect satisfaction. They also examine the effects of satisfaction on consumer complaints, product recommendations, and repeat purchase intentions. The findings in their survey show that satisfaction mediates the effects of positive and negative consumption-based emotions on complaints, recommendations, and intentions, even after controlling for confirmation of product expectations. Further, consistent with research in psychology, extraversion and neuroticism had strong effects on positive and negative emotions, respectively. A structural-equation methodology was used to test hypotheses.

Gould investigates mood and its relationship to self-regulation in the consumption of feeling-good products, particularly those alleviating bad moods. Using open-ended written protocols and an interpretive approach to analyze these data, he develops an emergent consumption and mood framework (CMF). The CMF maintains that consumers use products and services as tools for regulating their moods and achieving desired goals. Professor Gould stresses that self-reflection and consumptionspecific experiences are needed to understand the role of mood. In this way the intrinsic character of moods are revealed, in contrast to the use of standard paper-and-pencil scales, which lack deep connections to the consumption experience. It is involvement with product use that requires focus, Gould points out, rather than purchase per se. He also suggests that individual differences, such as gender, ethnicity, or personality, are expressed through mood management and consumption and frequently act as moderators. Finally, Gould notes that researchers need to consider consumption as a process and in an ongoing developmental sense rather than as an isolated response to situational stimuli. Throughout the article, the reader will get a sense of how a phenomenological approach can be used to gain insights into consumption. 


\section{CONCLUSION}

The articles in this issue show that consumer decision making is very much characterized by emotional processes and their role in purposive action. Emotions serve to motivate action, qualify information processing, and in general regulate the pursuit of consumption goals. As we learn more about the affective side of consumer behavior, we are likely to find that our theories, which are by and large cognitive in content, will require refinement. We are in need of more integrative theorizing to better explain and understand consumption. The articles in this issue provide a basis for such theorizing, but much remains to be done.

I would like to express my appreciation to Professor Rajan Nataraajan for asking me to coordinate this special issue. Actually, Rajan and I worked closely together throughout the process. I am indebted to him for his support and insights and am pleased and honored to be considered his friend.

Correspondence regarding this article should be sent to: Richard P. Bagozzi, Dwight F. Benton Professor of Behavioral Science in Management, School of Business Administration, The University of Michigan, 701 Tappan St., Ann Arbor, MI 48109-1234

\section{ACKNOWLEDGMENTS}

The input of the following reviewers, some of whom read two manuscripts each, is gratefully acknowledged:

Aaron Ahuvia

Gerald Albaum

Chris Allen

Raj Arora

Rajeev Batra

Hans Baumgartner

William Bearden

Sharon Beatty

Russ Belk

Joseph Bellizzi

Albert J. Della Bitta

Steve Brown

Robert Burnkrant

Bobby J. Calder

Meg Campbell

Kim Corfman

Pratibha Dabholkar

Julie Edell

Charles Gengler
University of Michigan Business School

University of Oregon

University of Cincinnati

University of Missouri, Kansas City

University of Michigan Business School

Pennsylvania State University

University of South Carolina

University of Alabama

University of Utah

Arizona State University W. Campus

University of Rhode Island

Southern Methodist University

Ohio State University

Northwestern University

University of California, Los Angeles

New York University

University of Tennessee

Duke University

Rutgers University 
Marvin Goldberg

Robert Green

Klaus Grunert

Judy Harris

Curtis Haughtvedt

Morris Halbrook

Michael J. Houston

Cynthia Huffman

Frank Kardes

Carole Macklin

Durairaj Maheswaran

David Mick

Andrew Mitchell

James A. Muncy

Richard Oliver

Richard Olshavsky

Jerry Olson

Thomas Page

Rik Pieters

Linda Price

William Qualls

Venkat Ramaswamy

Ed Rigdon

Julie Ruth

Joel Saegert

Joseph Sirgy

Robert Spekman

Michal Strahilevitz

Harish Sujan

Mita Sujan

David Szymansky

Patriya S. Tansuhaj

R. Kenneth Teas

Paula Tidwell

Prashanth Unnikrishnan

H. Rao Unnava

Robert Westbrook

John Wheatley

Arch Woodside

Youjae Yi
Pennsylvania State University

University of Texas at Austin

Aarhus School of Business, Denmark

University of Houston

Ohio State University

Columbia University

University of Minnesota

University of Pennsylvania

University of Cincinnati

University of Cincinnati

New York University

University of Wisconsin

University of Toronto

Valdosta State University

Vanderbilt University

Indiana University

Pennsylvania State University

Michigan State University

Tilburg University

University of South Florida

Massachusetts Institute of Technology

University of Michigan Business School

Georgia State University

University of Washington

University of Texas, San Antonio

Virginia Tech

University of Virginia

University of Michigan Business School

Pennsylvania State University

Pennsylvania State University

Texas A \& M University

Washington State University

Iowa State University

Charles Sturt University-Mitchell, Australia

Chapman University

Ohio State University

Rice University

University of Washington

Tulane University

Seoul National University 